\title{
ANÁLISIS SEMIOLINGÜÍSTICO DE UNA ENTREVISTA EN EL MARCO DE LOS DISCURSOS SOBRE MEDICINA POPULAR EN INSTITUCIONES DE SALUD
}

\author{
Elisa R. GIANUZZI ${ }^{1}$
}

\section{Resumen}

Este trabajo tiene como objetivo analizar una entrevista realizada a la esposa de un Machi (agente de medicina mapuche), desde un enfoque semiolingüístico, prestando especial atención a la lógica y mecanismos que generalmente sostienen a una producción lingüística. Para ello, nos remitimos a la utilización de las herramientas del análisis del discurso, en un sentido transversal e interdisciplinario. Abordaremos, además, algunas de las variables puestas en juego en los intentos de integración entre la medicina oficial y las prácticas en salud de las culturas indígenas.

Palabras clave: Semiolingüística- discurso- medicina- culturas indígenas- integración

Abstract

This work aims to discuss an interview with the wife of a Machi (mapuche medicine agent), a semiolinguistico approach, paying special attention to the logic and mechanisms that usually hold a linguistic production. To do this, we refer to the use of the analysis tools of discourse, in

\footnotetext{
${ }^{1}$ Licenciada en Psicología. Universidad Nacional de Mar del Plata. Correo electrónico: elisagianuzzi_05@hotmail.com
}

Fecha de recepción del artículo: Marzo 2014

Fecha de evaluación: Junio 2014 
a transversal and interdisciplinary sense. We will address, in addition, some of the variables implemented in game integration efforts between the official medicine and practices in health of indigenous cultures.

Key words: Semiolinguistica-speech-medicine - indigenous cultures - integration

\section{Résumé}

Ce travail a pour but de discuter d'une entrevue avec la femme d'une Machi (agent de médecine mapuche), une approche de semiolinguistico, en accordant une attention particulière à la logique et des mécanismes qui tiennent habituellement une production linguistique. Pour ce faire, nous nous référons à l'utilisation de l'outils d'analyse du discours, de manière transversale et interdisciplinaire. Nous aborderons, en outre, certaines des variables mises en œuvre dans les efforts d'intégration de jeu entre la médecine officielle et les pratiques en matière de santé des cultures autochtones.

Mots clés: Semiolinguistica-discours-médecine - cultures autochtones-intégration

\section{Introducción:}

En el presente trabajo analizaremos, desde un enfoque semiolingüístico ${ }^{2}$, una entrevista en profundidad realizada por una docente en Enfermería ${ }^{3}$, a la esposa ${ }^{4}$ de un Machi. Desde

\footnotetext{
${ }^{2}$ Se escoge dentro de la Etnografía del Habla a la visión semiolingüística para el análisis de la entrevista. Recordemos que la Etnografia del Habla se centra en una visión del tratamiento del discurso como texto, como práctica social y como ámbito de manifestación de la lucha por el poder hegemónico en el que se articulan, desarticulan y rearticulan los contextos y las identidades (Fairelough, 1992 en Fernández, 2004).

3 Ángela Castellano Salas es Profesora Adjunta en la Escuela de Enfermería, Pontificia Universidad Católica de Chile. Autora del texto: "Guardiana del espíritu de un machi y sus sueños" (2007), en el que nos basaremos en este trabajo.

${ }^{4}$ Según la autora, María tendría, al momento de la entrevista, alrededor de 52 años de edad. Cursó sus estudios primarios hasta $7^{\circ}$ básico, vivió hasta la adolescencia en una comunidad con alta población mapuche, al sur de Chile. Lugar en el que convivía con sus tíos, ya que sus padres fallecieron cuando María tenía dos años, y en esa familia fue que aprendió a valorar las enseñanzas de la tradición o legado
} 
encuadre semiolingüístico se utiliza a la semiótica como ciencia explicativa y a la lingüística, como ciencia instrumental.

Tanto la entrevistadora, como el Machi y su esposa, trabajan en un centro de salud intercultural de Santiago de Chile. En este centro, se ofrece a los usuarios ${ }^{5}$, la posibilidad adicional de acceder a la medicina mapuche, con la finalidad de complementar ambos sistemas de salud: el oficial y el campesino ${ }^{6}$.

Nos basaremos en el texto original de la entrevista, tal como fue transcripto por la entrevistadora, respetando el formato, sin incluir sus intervenciones durante el transcurso de la misma. Análisis que luego fue efectuado por Castellanos Salas (2007) en su artículo "Guardiana del espíritu de un machi y sus sueños"7.

Prestamos especial interés a la lógica y mecanismos que generalmente sostienen a una producción lingüística, desde el análisis del discurso, en un sentido transversal e interdisciplinario. Como hipótesis central planteamos que la insistencia por parte de María para dar cuenta del "poder de sanación" de su marido y del rol que ella misma cumple en relación con ese don, estaría orientado en la recurrencia al justificar, la función que ambos desempeñan en el sistema de salud. Lo que indicaría posibles dificultades en la integración de ambas medicinas (popular y oficial) desde el imaginario social.

de los antepasados. Alrededor de los 15 años de edad, se trasladó a trabajar a Santiago de Chile, allí conoció posteriormente, a Manuel Lincovil, su esposo con quien tienen tres hijos.

${ }^{5}$ Preferimos hablar de "usuarios" y no de pacientes, ya que ésta última acepción en salud, responde a una relación asimétrica de poder, que impide, entre otras cosas, un reposicionamiento subjetivo de quien padece un sufrimiento mental o físico.

${ }^{6}$ Término que suelen emplear en nuestro país (Argentina), los usuarios, para dar cuenta de las prácticas en salud que autores como Agustín Fernández, denominan como "Medicina Popular". Ver "El rol de la medicina popular en el NOA" en: "Cuaderno de ética, estética y religión III" (2009)

${ }^{7}$ Disponible en: http://scielo.isciii.es/scielo.php?pid=S1132-12962007000200014\&script=sci_arttext 
En este relato que oscila entre una biografía y una elección autobiográfica, veremos como la Eda escoge una forma viable para ser aceptada por el A (Otro) ${ }^{8}$ (Lacan, 1961-62), y/o entablar una polémica con él, encarnado en este caso, en las instituciones, salud y educación, e identificadas en la persona del Er.

En cuanto a la opción genérica, para justificar su posición, escoge argumentar como un narrador que fluctuará por momentos entre un relato con focalización interna en un narrador homodiégetico, y por otro lado, como un narrador de tipo autodiégetico (Genette, 1983 en Fernández, 2006).

María presupone al otro como representante de un discurso antagonista con quien instaura una polémica. Elige para ello, una singular ubicación en el tiempo y en el espacio. En su relato predomina el uso de un modo verbal fáctico (indicativo), junto al de conectores causales, para demostrar los obstáculos que aún debe superar con el objetivo de acompañar y fortalecer el "Don" de la sanación en su marido, devenido Machi. Finalmente, consideramos que incluye a testigos que la avalen y construye la figura del héroe, con la cual parecería identificarse ${ }^{9}$.

${ }^{8}$ El Otro (A) designa la alteridad radical, la otredad que trasciende la otredad ilusoria de lo imaginario, porque no puede asimilarse mediante la identificación. El gran Otro es lo simbólico en cuanto está particularizado para cada sujeto; como lo señala Evans (1997: 143) "el Otro debe en primer lugar ser considerado un lugar, el lugar en el que está constituida la palabra". En otros términos, "El Otro es el lugar donde se sitúa la cadena del significante que rige todo lo que, del sujeto, podrá hacerse presente, es el campo de ese ser viviente donde el sujeto tiene que aparecer" (Lacan, 1961-62:212)

${ }^{9}$ La identificación implica una apropiación, un punto de vista, un lugar ideal marcado en el campo exterior del sujeto, desde el cual se sitúa para poder sostener su deseo. Para Lacan (1961-62), la identificación solo es posible concebirla dentro de los términos de la dependencia de la formación del sujeto en relación a los efectos del significante: “(...) nada soporta la idea tradicional filosófica de un sujeto, sino la existencia del significante y sus efectos. Una tesis tal (...) será esencial a toda encarnación que (...) podamos dar de los efectos de la identificación, exige que intentemos articular más precisamente 


\section{Texto de análisis: “Guardiana del espíritu de un machi y sus sueños”.}

Entrevista realizada por la profesora y enfermera Ángela Castellano Salas a María (esposa de un Machi), en un espacio del sector de la salud pública chilena, en el que se intenta articular la medicina oficial con la medicina popular y/o campesina. Dicha entrevista fue grabada y transcripta en forma completa y textual por la autora, formato que será respetado a continuación, incluyendo, entre corchetes, los comentarios de la entrevistadora.

La entrevista está organizada según los siguientes tópicos:

A) Primeras señales de la enfermedad de machi.

B) Sueño revelador.

C) Antepasados machi en su familia.

D) La enfermedad sigue, hay que confirmar el don.

E) Preparándolo para que asuma el don.

F) El poder de las pruebas en la aceptación del don.

G) El camino es difícil.

H) Los sueños me dicen cómo cuidar su espíritu.

I) Mis deseos.

A) PRIMERAS SEÑALES DE LA ENFERMEDAD DE MACHI. Para mí fue muy difícil y es todavía. Cuando empezó, el año 82 parece que fue, él trabajaba en una empresa, es contador y llegaba de repente a la casa y se sentía mal. Estaban chicos mis hijos, me decía siempre "Maruja yo no quiero bulla, no quiero bulla". Ya ahí lo dejábamos pasar y entonces como los niños chicos son inquietos, ellos que entran y sale, me decía "pero mejor echa a acostar los niños cuando yo llegue, ¡los niños tienen que estar acostados!”.

como concebimos efectivamente esta dependencia de la formación del sujeto en relación a la existencia de efectos del significante como tal" (ver Lacan, 1961-62). 
Entonces yo le decía “¿pero porqué, si ellos quieren jugar?”. Y en un momento yo dije, bueno "iporqué, qué pasa con él, porqué está así!" [sube el tono] ${ }^{10}$.

Después llegaba del trabajo, me decía "me siento muy mal, no puedo usar zapatos, me duelen los pies"; pasaba así, al otro día llegaba él y decía, "no puedo comer" y yo al final lo retaba, "¡tienes que comer!, ¿por qué no quieres comer, dime qué te pasa?" [Tono más firme, recalcando cada palabra]. Pero yo presentía que algo tenía él, por eso le pasaban esas cosas.

B) SUEÑO REVELADOR. No decía él [refiriéndose a la posibilidad de ser machi], pero yo tenía esa corazonada, porque yo antes tuve un sueño, yo creo mucho en mis sueños, yo me soñaba que lo andaban trayendo en una carreta de campo y lleno de remedios (para los mapuches son las hierbas medicinales). Es como la virgen cuando la llevan, así lo llevaban, pero lleno de remedios, de hojas de maqui (hierba medicinal de propiedades sagradas), de canelo y él estaba tapado así y entonces yo decía "¿por qué pasará esto, por qué?". Cuando recién nos casamos me soñaba así.

C) ANTEPASADOS MACHI EN SU FAMILIA. Nosotros vivíamos con una prima de él, que en paz descanse; yo confiaba en ella y nos contábamos los problemas, ella me quería mucho, yo a ella igual, como una hermana. Me decía “¿cómo encuentra a Manuel?”; yo le decía, "no lo encuentro bien, no se qué le pasa". Y ella me decía "algún día el Manuel va a ser machi". "Quizás", le decía yo, "porque a mi me dan muchos sueños y me pasan cosas, ¿por qué?". Ahí me decía ella "si sus antepasados eran machi, ¿tu conociste alguno?". "Si" le decía yo, "conocí a la tía del que era machi, era muy buen machi".

Ahí fuimos al sur, a mi suegra le conté, "¿por qué Manuel se enferma tanto? y yo me he soñado que él anda en esto, en una cosa verde lo andan trayendo". Me dijo mi suegra "ni por ná, no se te ocurra comprar platería, no diga voy a tener platería ahí". “¿Porqué?”, le dije yo, "a mi me gusta tanto la platería, tal como en todas las prendas y me gusta tenerlo en la casa, tener como adorno...". [me aclaró otro día que la plata atrae al espíritu de

${ }^{10}$ Los comentarios entre corchetes a lo largo de la entrevista transcripta pertenecen a la entrevistadora y autora del texto: “Guardiana del espíritu de un machi y sus sueños” (2007). 
machi y la mamá no quería que su hijo fuera machi, porque sufren mucho]. Así estábamos solas conversando y ahí me dijo "¿a lo mejor usted conoció mi antepasado de machi?, en una de esas puede ser machi Manuel o uno de sus hijos o hija y yo a nadie le he contado eso, yo lo tengo en mi no más". Ella me contaba todo porque me tenía confianza, no tenía una hija y para mi ella era como una madre y yo como una hija. Yo no le dije tampoco; ella me dijo [su suegra], "él se va a ir dando cuenta solo".

D) LA ENFERMEDAD SIGUE, HAY QUE CONFIRMAR EL DON. Él se enfermó ${ }^{11}$ más después que se le murió su mamá, el papá, se sentía mal. Decían “donde está solo y no tiene la mamá o la mamá sabía que él iba a ser machi y nunca dijo nada, no le dijo a su hijo, por eso él está pasando as'́". [se nota triste al recordar eso]. Todo eso lo tenía él, como que no quería contarlo, lo tenía guardado todo. Yo pienso que era temor, miedo que él fuera machi. Es difícil, difícil asumirlo.

Dije yo, “¡no me puedo quedar así, tengo que descubrir qué está pasando!” y como no había machi acá, lo llevé a un espiritista que ven por las manos. Y ahí el caballero fue honesto, me dijo "hay algo en su marido que lo persigue, pero está más en ti que en él, el espíritu, para eso las prendas, todo, tu estai vestida de machi”. Le dije "¿pero qué va a pasar entonces?". "No se", me dijo, "pero algún día se irá a saber, si usted no cree, vaya a una machi del sur". "Ya", le dije, "lo voy a hacer, voy a ir a la machi".

Y ahí yo lo llevé a la machi allá, le llevé la orina me acuerdo, es que cuando yo sé algo, no me quedo tranquila, tengo que descubrirlo y mis hijos son igual [ríe fuerte, como con orgullo de esa característica suya]. ¡Es que estaba mal, tenía que ir!. Ahí le dijeron a Manuel que iba a ser machi y "si no toma su responsabilidad, va a quedar en silla de ruedas; ahí verá él qué va a hacer, si lo va a tomar o no". [baja la voz, como recordando el pesar que le produjo]. Ella me había dicho, "vaya donde otra machi"; "pero mamita", le hablé así me acuerdo, "ya llegué en tu casa, en tu mano, ya llegué y confié en ti, no puedo

11 “La enfermedad es vivida como manifestación de su vocación, ocurre antes de su iniciación y puede repetirse para recordarles su llamado. Las personas que no reconocen la invocación serán castigadas por no seguir el llamado de Ngünechen: permanecen enfermos por el resto de sus vidas y eventualmente mueren" (Castellano Salas, 2007). 
ir a otro. Yo quiero saber ¿qué va a pasar con él más adelante?”. Me dijo "al final va a tomar su don, tu tienes que apoyarlo".

E) PREPARÁNDOLO PARA QUE ASUMA EL DON. Le hice un tratamiento grande con toda su gente allá en el campo, le hicimos una ceremonia con otras machi ${ }^{12}$, no pueden ellos levantarse solos. De ahí se sintió bien, se mejoró, como la machi le hizo una sanación (en la medicina mapuche se refiere a distintos rituales que van desde los más simples u oraciones hasta los más complejos, llamados machitunes), le agradó al espíritu. Después le pregunté a ella, “¿bueno y qué va a pasar con él más adelante?”. Me dijo, "déjelo solito, él sabe qué lo que va a pasar, tiene que tener sus instrumentos para que haga oraciones, pero van a pasar muchas cosas, le van a venir muchas pruebas, a él".

Después nos vinimos a Santiago y acá seguía enfermo. Yo la llamaba a la machi y le decía "pasa esto, se enferma ¿por qué?" y me decía ella "bueno tráigalo". Yo iba para allá a conversar con ella y la traía para que le venga a hacer oración, por eso le tengo mucho agradecimiento a la viejita, todavía está viva. Entonces era yo la que decía, "tienes que hacer esto, tienes que hacer esto otro". Cuando él se recibió en un momento, yo pasaba puro llorando, no dormía, de eso me enfermé de la úlcera.

Con esa machi teníamos contacto y después ella dijo "tienen que buscar un lugar donde estar porque aquí están mal en departamento, porque él tiene que tener su rewe (poste tallado o altar de machi) al frente, donde sale el sol tiene que tener la puerta". Entonces ahí nos cambiamos y buscamos un lugar.

F) EL PODER DE LAS PRUEBAS EN LA ACEPTACIÓN DEL DON. Le costó aceptar. Yo pienso que tomó la decisión porque no estaba muy bien en la casa, se enfermaba mi hijo, hay veces era como un hospital la casa y mi hijo mayor casi se me fue [baja el tono

\footnotetext{
12 "Las machi son las intermediarias entre el mundo mapuche y el mundo sobrenatural y sus espiritus protectores les entregan poderes para combatir a los espiritus malignos. Velan por el bienestar de sus enfermos y la comunidad (...) Se usa el término machi en femenino porque la mayoría son mujeres, y los hombres tienen el espíritu femenino también y se expresa en singular, de acuerdo a la lengua mapuche, el mapudungun" (Castellano Salas, 2007).
} 
de voz]. Entonces ahí las machi me dijeron, "te están tomando los hijos, te están tomando las pruebas, ¿qué es lo que va a hacer?; si realmente cree, tiene que tomar el don".

A mis hijos no les gustaba, yo pienso porque como ellos nacieron y el papá no era machi. Cuando nos sentábamos a conversar, estábamos solos sirviéndonos algo y me decían "pero mamá, por qué mi papá se hizo machi, ipara qué!”. "Hijo”, le dije yo, “¿para qué se hizo machi?, para ayudar a la familia, para ayudar a la gente y también si no es machi puede quedar en silla de ruedas, porque el daño es muy complicado, si tu no toma responsabilidad o no asume, te pasan cosas y te dan pruebas de arriba. Entonces, por eso el tomó la responsabilidad y todo este trabajo y el peso que llevo yo" [deja entrever la carga que le toca a ella].

G) EL CAMINO ES DIFÍCIL. Igual tenía que apoyarlo porque se sentía mal, a veces yo misma le hacía la oración, le preparaba los remedios y ahí me despertaban [el espíritu] a las 5 de la mañana, "ique se levante su machi, que haga oración!". Entonces cuando se levantaba, hacía oraciones, de ahí venía a dar mensaje el espíritu, ahí yo tenía que recibir el mensaje. Porque en las hierbas, cuando falta una hierba, en sueño me dicen, falta tal hierba en la ola.

¡Pero fue tan difícil todas las cosas! Problemas de la gente que hablaban, los mismos hijos, que no querían aceptar, en un momento me dijo "no voy a atender más gente". Yo le dije “ ¡no, tu quisiste tomar el don, tenís que seguir adelante, no podís echarte pie atrás! ¿qué van a decir los mismos pacientes que usted ha sanado?" [En un tono firme y cuestionador].

Desde que empezó es difícil, pero ahora es más. Uno ve tantas cosas, da mucha pena, pasan por tantas cosas los machi. No los quieren bien, algunos le tienen mala, envidia por todos lados, no es fácil. Están en la mira de todos, en qué se tropieza, en qué cae, es complicado.

H) LOS SUEÑOS ME DICEN COMO CUIDAR SU ESPÍRITU. Yo creo en mi sueño, en sueño me dijeron "el no puede como machi, no puede meterse mucho en periodismo, que lo graben, porque le quitan una parte del espíritu, del alma". Una vez, dos veces, está bien, pero no todo el tiempo estar metido ahí grabándolo, sacándole fotos. Es que la fama lo sube y a la vez lo tira al hoyo. ¡Es muy peligroso! Mis antepasados decían siempre la foto no sirve, porque una foto como que te decae, te quitan una parte de tu espíritu, debilitan el pülle (espíritu) como decimos nosotros y al final en vez de hacer bien las cosas se van por el otro lado. 
Varias veces me dijeron en sueño, "tu tenís que hablar, tu tenís que decir esto". Todo me van diciendo en sueño lo que va a pasar, cuando va a haber algo, me da el sueño primero y después pasa [alude a una visita que ella le llamó la atención a un médico que grabó sin permiso]. Era una máquina chica, una grabadora y me colocaban el micrófono, entonces yo decía "no, yo no quiero micrófono" y me buscaban así, "¡no, si no quiero”! [sube la voz, expresando enojo]. Me corría y me iba para otro lado. Yo decía "¿qué irá a pasar, porqué me habré soñado así?".

Como me dijeron [en sueño], "esto y esto va a pasar, tu tienes que estar aquí y no alejada de eso", ahora voy a las reuniones para ver de qué se trata, para entender más y uno tiene que estar porque está trabajando en salud con los doctores. A mi hijo igual le digo, a mi hijo mayor sobre todo, tu tenís que meterte más, apoyar, ayudar, si hay evento tenís que ir.

I) MIS DESEOS. Me gustaría que la gente fuera más respetuosa con la gente espiritual, por ejemplo con el machi. Porque ahora que estamos aquí en la ciudad, todo el mundo quiere ser machi, porque está trabajando piensan que está sentado encima de la plata y no es así, porque los machi también tienen sus gastos, la casa.

Eso es lo que yo siempre pido a Ngünechen (deidad Mapuche), que se recuperen las cosas antiguas, la cultura, como era antiguamente. Porque la gente ahora no conoce la parte espiritual, no se valora y yo pienso también que como ellos tienen educación [los jóvenes] entonces creen que ellos saben más que los que no tienen educación.

\section{Análisis e Interpretación:}

\section{II.a) La dimensión argumentativa del relato y la presuposición del discurso del otro como antagonista}

Para analizar la entrevista, desde un abordaje semiolingüístico, consideramos como punto de partida aquello que nos resulta más llamativo en el discurso de María, esto es: el sesgo argumentativo que se presenta de manera recurrente a lo largo de la narración. El discurso 
de la entrevistada parecería estar intencionado hacia la aceptación de su postura por parte de un otro $^{13}$.

Como sostenemos en párrafos introductorios, este relato, que fluctuaría entre una opción genérica, de tipo biográfica y una elección autobiográfica (registrada en la reiteración a la referencia al yo pronominal), nos permite pensar en los modos en qué María intentaría demostrar a la entrevistadora y al Otro de la cultura (Lacan, 1961-62) la complejidad, el padecimiento sufrido, los temores vivenciados por ser una "intermediaria" -entre los espíritus y su esposo- o, remitiéndonos a la mención que hace la autora del trabajo citado, como consecuencias de ser: "Guardiana del espíritu de un Machi".

Si bien la entrevistadora refiere "ser representante de la cultura mapuche", por su labor como enfermera, representa también al sistema de salud oficial. De manera tal que, por debajo de lo que no se dice, la interpretación subjetiva del contexto de la entrevista, elaborado por los participantes del discurso (Edo- $\mathrm{Er}^{14}$ ), se hallaría en constante construcción y transversalizado por las normas, valores, reglamentaciones, etc. de las instituciones de salud. Al principio de la entrevista, María no menciona, explícitamente, que se venía hablando del don de machi de su esposo. La entrevistadora lo aclara en uno de los apartados: "No decía él [refiriéndose a la posibilidad de ser machi], pero yo tenía esa corazonada". En este caso, María utiliza un conector contraargumentativo fuerte "pero", para continuar la oración. Lo que denota que la conclusión es contraria a la esperada. En toda entrevista se pone en juego al principio un tipo de ansiedad paranoide (Bleger, 1964), producto del desconocimiento de la situación nueva a enfrentar. En base a esto podemos sostener que el discurso de María está determinado por los efectos de una regla subyacente socialmente avalada por el discurso del "modelo médico hegemónico", aun vigente en las instituciones de salud y reforzado por los mecanismos del mercado capitalista, que inducen un consumo exacerbado de los productos de la industria farmacéutica. La regla que subyace a los mecanismos del capitalismo farmacéutico podría ser

\footnotetext{
${ }^{13}$ En este sentido, Lo Cascio (1991, en Fernández, 1998), expresa: “La argumentación tiene una función justificativa. Toulmin considera, por lo tanto, la opinión propuesta en una argumentación, una petición o pretensión (claim), en cuanto el hablante busca obtener el consenso del oyente".

${ }^{14}$ Edo: entrevistado. Er: entrevistador. De aquí en mas se utilizarán estas abreviaciones para mencionar estos conceptos
} 
expresada en la siguiente frase: "se cura con remedios, y cuanto sean estos más publicitados y costosos mejor". El término "remedios" es utilizado en las culturas indígenas como producto del sincretismo cultural en el que un grupo hegemónico (Gramsci, 1978), el de la "sociedad civil", se impone sobre otro. Ancestralmente, para asistir distintos malestares, las/os "machi" utilizan hierbas como el maqui (que tiene propiedades sagradas), entre otras, a las que también se suelen denominar como "medicinales". Es decir que, en esta sustitución, también se visibiliza el poder ejercido de la medicina oficial sobre las prácticas en salud de las culturas indígenas. Esto último, se registra cuando María continúa con la siguiente expresión: "Es como la virgen cuando la llevan, asi lo llevaban, pero lleno de remedios". Nuevamente María elige el conector contraargumentativo fuerte "pero", en este caso, para aminorar el carácter religioso al que hace referencia cuando compara, el modo en que llevaban a su marido en el sueño, con la forma en cómo se traslada el altar de la virgen durante la procesión. De esa manera, consideramos que María justifica el rol de asistente en salud de su marido, como lo hace en varias oportunidades a lo largo de la entrevista.

\section{II.b) La instauración del diálogo polémico: ¿Medicina intercultural?}

Más allá de algunas experiencias en transformación en las que se intenta complementar ambos saberes, la "medicina campesina" y la medicina oficial, aún están vigentes, en el imaginario social, el reconocimiento de la eficacia de solo una de estas prácticas. Lo que puede ser inferido a partir de lo enunciado por María, al referirse a "los doctores" en tercera persona, denotando una ausencia de articulación de ambos saberes ${ }^{16}$. María plantea poseer un saber que

${ }^{15}$ Definida por Gramsci (1978) como el conjunto de los organismos "vulgarmente llamados privados" y que corresponden a la función de hegemonía que el grupo dominante ejerce en toda la sociedad (...). La sociedad civil es una totalidad compleja que se manifiesta como ideología de la clase dirigente expresada en el arte, las ciencias, la economía, el derecho, etc. (...). Así considerada, la sociedad civil coincide con el campo de la ideología.

${ }^{16}$ Relata María: "Como me dijeron [en sueño], "esto y esto va a pasar, tu tienes que estar aquí y no alejada de eso", ahora voy a las reuniones para ver de qué se trata, para entender más y uno tiene que estar porque está trabajando en salud con los doctores". 
le fue dado a través de un sueño, utiliza para referirse al mismo, las formas deícticas cercanas al yo "esto y esto", sin decir qué fue lo transmitido. Posicionándose frente a la entrevistadora en un lugar de saber-poder (Foucault, 1978), "lucha de poder que se pone de de manifiesto en la práctica discursiva de la entrevista" (Fernández, 1999). Luego, la entrevistada contrasta con lo que sigue: "ahora voy a las reuniones para ver de qué se trata". Este "desconocimiento" podría estar relacionado con la medicina oficial, ya que se refiere a "los doctores" en tercera persona, utilizando el deíctico "eso" (forma deíctica próxima al tú), al mencionar a las reuniones del centro de salud. Así como, parecería aludir a un saber "omnipotente" que no está dispuesta a compartir con la entrevistadora, más allá de que ésta se identifique explícitamente con las culturas indígenas. Utiliza un cuantificador "todo" para dar cuenta de ese saber, en la siguiente expresión: "Varias veces me dijeron en sueño, tú tenís que hablar, tú tenís que decir esto. Todo me van diciendo en sueño lo que va a pasar", lo que legitima el discurso y la posiciona en el lugar de saber o como voz de autoridad ${ }^{17}$.

En cuanto a la vinculación con la Diégesis (Genette, 1987), el relato de la entrevistada parecería ser el de un narrador que oscila por momentos, entre un relato con focalización interna en un narrador homodiégetico, reflejada en la deixis próxima al yo y en preguntas retóricas ${ }^{18}$ como: “por qué pasará esto, por qué?” ; y por otro lado, aparece un narrador de tipo autodiégetico, de ahí que María expresa: "yo antes tuve un sueño, yo creo mucho en mis sueños,

${ }^{17}$ El discurso por lo tanto, no es algo terminado sino que se trata de una "acción en curso" (Van Dijk, 1997), en términos del autor: "los contextos no influencian en absoluto, directamente, al discurso o al uso del lenguaje. Más bien, es la interpretación subjetiva del contexto que hacen los participantes del discurso lo que limita la producción discursiva, la estructuración y la comprensión. Es decir, dado un hecho comunicativo en una determinada situación social, sus participantes activa y continuamente construyen una representación mental de sólo aquellas propiedades de la situación que le son relevantes" (Van Dijk 1997, en Fernández, 1999).

${ }^{18}$ La pregunta retórica es una forma alusiva/elusiva. En cuanto se plantea la interrogación, se presupone un alocutario que posee un poder en tanto tiene capacidad de respuesta, pero no bien no se atiende a ella, adelantándose y dando una el propio locutor, se coloca, nuevamente, al alocutario en una posición de no saber y no poder (Fernández, 2011). 
yo me soñaba que lo andaban trayendo en una carreta de campo y lleno de remedio ${ }^{19}$ ". En este sentido, la entrevistadora, en su análisis, resalta su dificultad para "manejar la entrevista", expresando lo siguiente: "Si bien la conversación fue fluida, no fue fácil el manejo de la entrevista, pues se entrecruzaban las historias del machi con las de ella".

Partiendo desde el principio básico de la narración, que considera que siempre hay un narrador y un narratorio, por momentos parecería que el destinatario -es decir el receptor a quien va dirigido auténticamente el mensaje- estaría posicionado por María como alguien que cae en su égida simbólica. Sin embargo, en otros momentos, el destinatario parece representar, en la figura de la entrevistadora, al antagonista. Más allá de los cambios visibilizados en el centro de salud, en que se complementan los conocimientos médicos, la insistencia por parte de María en su argumentación (por ejemplo, a través del recurso de utilizar un modo verbal fáctico) indicaría, desde el imaginario de este actor social, una ausencia de integración de ambas prácticas, como fue mencionado anteriormente. Hacia el final de la entrevista María se dirigiría a un antagonista generalizado en el siguiente término: "la gente"20.

\section{II.c) Ubicación temporo- espacial}

Si bien el tiempo de una enunciación suele ser el presente, en nuestro caso se producen “quiebres en la temporalidad" (Genette, 1987 en Fernández, 2006) en los que se relatan eventos anteriores al del momento de la enunciación, es decir, retrospectivos, intercalándose con eventos prospectivos. En una misma oración se mezclan, en el relato de María, un dominio de la aspectualidad vinculado a un tipo de acción culminativo con otro durativo. Así, por ejemplo, comienza la entrevista diciendo: "Para mi fue muy dificil y es todavia"; continuando con la frase: "Cuando empezó, el año 82 parece que fue", en la que el dominio de la modalidad es de tipo "epistémica", expresada en el uso de la palabra "parece" o en la expresión "Yo creo" en la

19 "Remedio" y "Sanación" (palabra que aparece en otra parte de la entrevista) funcionan como “psiquemas". Se trata de referentes psicoculturales, teorizados por Fernández Güizzetti, (1983)

20 "Me gustaría (modo verbal no factico) que la gente fuera más respetuosa con la gente espiritual” o, "yo pienso también que como ellos tienen educación [los jóvenes] entonces creen que ellos saben más que los que no tienen educación". 
que además se registra la asunción del yo. En este primer párrafo, se registran además, cambios en el funcionamiento de la deixis ${ }^{21}$.

María se va acercando y/o alejando a través del uso de adjetivos y pronombres demostrativos, al uso de adjetivos y pronombres posesivos, como por ejemplo: "mis hijos". Se registra una diferencia significativa entre lo dicho, según la entrevistada, por el marido, al referirse a la misma como "Marucha", y el modo en qué ésta última lo alejaría inconscientemente de su yo utilizando el pronombre "él" para referirse al esposo. Esta modalidad se reitera a lo largo de la entrevista, "Nosotros vivíamos con una prima de él", el "nosotros" funcionaría como un "nosotros exclusivo". Tal cualidad, también se registra en los momentos en que se refiere al hogar, para los que utiliza la adjetivación: "la casa", "me gusta tenerlo en la casa”.

El espacio geográfico en el que se desarrollan estas vivencias, es el de una ubicación del topus como espacio heterotópico (Greimás y Courtes, 1979 en Fernández, 2006): "allá en el campo", diferente al modo en que se expresa al mencionar el lugar actual de residencia: "aqui en la ciudad", "Después nos vinimos a Santiago", teorizándose estas últimas expresiones, como "espacio tópico", según Greimás y Courtes (1979, en Fernández, 2006) ${ }^{22}$. Se expresa en el discurso dos territorialidades ${ }^{23}$ diferentes, vivenciadas y experimentadas por el mismo actor:

${ }^{21}$ Los cambios en el funcionamiento de la deixis se visualizan en la siguiente expresión: "él trabajaba en una empresa, es contador y llegaba de repente a la casa y se sentía mal. Estaban chicos mis hijos, me decía siempre "Maruja yo no quiero bulla, no quiero bulla". Ya ahi lo dejábamos pasar y entonces como los niños chicos son inquietos, ellos que entran y sale, me decía "pero mejor echa a acostar los niños cuando yo llegue, jlos niños tienen que estar acostados!”. Entonces yo le decía “¿pero por qué, si ellos quieren jugar?". Y en un momento yo dije, bueno "iporqué, qué pasa con él, porqué está asi!!" [sube el tono"].

${ }^{22}$ En este punto debemos considerar que se trata de una aproximación hipotética, y que en todos los casos es indispensable tener en cuenta las diferencias culturales al momento de expresarnos.

${ }^{23}$ Por territorialidad entendemos, en términos de Gómez Montañés (2001), el grado de dominio que tiene determinado sujeto individual o social en cierto territorio o espacio geográfico, así como el conjunto de prácticas y sus expresiones materiales y simbólicas, capaces de garantizar la apropiación y permanencia 
la ruralidad (el origen, la raíz de las familias mapuches post-conquista) y la urbanidad (el destino final de las corrientes migratorias internas de América Latina), a las que le asigna tanto un valor simbólico como material. Así el espacio tópico se define también en un tipo de discurso que Hernández (com. per., 2012) denomina "territorial", al estar el mismo expresando experiencias pasadas, presentes y futuras, directamente determinadas por el territorio con el cual se identifica el sujeto (sentido de pertenencia y añoranza), lo rechaza (sentido de destierro, confrontación y/o discriminación) o del que anhelaría formar parte desde su imaginario (sentido de futuro deseado).

\section{II.d) Los conectores causales en la argumentación y la construcción del héroe}

En la primera parte, la entrevistada utiliza recursos lingüísticos y discursivos predominantemente del tipo argumentativo, por medio de los cuales intentaría obtener el consenso y/o entablar una polémica con el Otro de la cultura, encarnado en este caso, en las instituciones de salud pública y de la educación. María, durante el comienzo de la entrevista, fluctúa entre la elección de conectores ${ }^{24}$ causales y consecutivos $^{25}$. En dos oportunidades, utiliza

de un territorio dado bajo determinado agente individual o social. Los sujetos que ejercen territorialidades pueden ser individuos, grupos sociales, grupos étnicos, empresas, compañías transnacionales, EstadosNación o grupos de Estados-Nación.

${ }^{24}$ Los conectores son piezas léxicas cuyo significado "constituye una especie de instrucción que se da al interlocutor, del tipo de: ' lo que sigue constituye la causa de lo que se ha dicho antes ' (significado, por ejemplo, de porque) o 'lo que viene a continuación es la conclusión que se deduce de la información anterior ' (instrucción de, entre otros, por lo tanto), etc. Así pues, los conectores, en general, tiene un significado que consiste en una instrucción para el interlocutor sobre cómo tiene que procesar las informaciones que se plantean en el enunciado.

(...) el significado de los conectores consiste en una instrucción al receptor para que procese la información que sigue a la partícula conectiva manteniendo con la información precedente un determinada relación (por ejemplo, causa - consecuencia: argumento- contraargumento; hipótesis consecuencia; nueva información sobre el mismo tema, etc)” (Montolío, 2001 en Fernández, 2006).

${ }^{25}$ Lo conectores consecutivos tienen como significado básico indicar que la información que les sigue constituye una consecuencia derivada de la información que antecede, lo que "resulta especialmente productivo para llevar a cabo la operación argumentativa de la demostración, pues la demostración 
el conector "entonces" -que señala inequívocamente hacia la consecuencia- al que le sigue la pregunta retórica ¿por qué pasará esto? Esto significa que la protagonista focalizaría más en la consecuencia que en la causa, para concluir luego con una respuesta en la que anula la posibilidad del alocutario de proponer alguna otra interpretación, ya que con la expresión: "Pero yo presentía que algo tenía él, por eso ${ }^{26}$ le pasaban esas cosas", María explica que sus sueños y presentimientos estaban asociados al malestar de su marido, producto del "llamado a ser machi”.

En la frase inicial, recurre al adverbio "muy" como elección léxica que implica una gradualidad sobrerealizadora: "Para mi fue muy difícil y es todavía", lo reitera nuevamente cuando, por ejemplo, vuelve a relatar la historia del marido en sus inicios como machi: "me decía: me siento muy mal”. Consideraríamos que, además de empezar el relato donde "pone el foco", inconscientemente, comenzaría a construir un personaje, con el que parece identificarse: el héroe.

La construcción de la figura del héroe, por momentos se personificaría en el rol "pasivo" 27 de su marido, aunque en la mayor parte de su relato, encontramos indicadores que

consiste, precisamente, en exponer y probar cómo desde una premisa o argumento concretos se llega a la conclusión a la que interesa llevar al receptor. De ahí la presencia recurrente de este tipo de expresiones conectivas en cualquier texto que presenta características argumentativas". (Montolío, 2001 en Fernández, 2006).

${ }^{26}$ Con la elección del conector "por eso", María introduce la consecuencia pero señalando de ella que es el resultado de la causa precedente.

${ }^{27}$ En varias oportunidades, al referirse a su marido, María lo ubica en una posición pasiva. Si bien, ella es la intermediadora entre él y los espíritus, la Eda focaliza recurrentemente, en los obstáculos que ha debido superar para que su marido acepte el don de machi. En un primer momento de la enfermedad del esposo, y al no conseguir a un machi a quién consultar, María visita a un espiritista al que luego de su intervención, considerara un "caballero honesto" por haber expresado la siguiente afirmación: "hay algo en su marido que lo persigue, pero está más en ti que en él, el espíritu, para eso las prendas, todo, tu estai vestida de machi". Una vez recibido el don, María se refiere a su "activo" rol como intermediadora 
nos orientan hacia un desarrollo de esa construcción heroica en la que se produce una transformación en María, al asumir esa imagen como propia, mediante identificación (Lacan, 1949).

El tema que elige para validar la argumentación sería el de "los obstáculos que tiene que superar", justificación que se vincula con la construcción heroica que mencionábamos antes, y que se registra en la remisión al hoy de la enunciación en la siguiente expresión: "pero ahora es más" (en la que se refiere a las dificultades que le ocasionaría la aceptación del don de machi). También, cuando menciona las pruebas que debe atravesar, y/o cuando dice: "el peso que llevo yo". Así como, cuando elige el conector antiorientado en posición de enlace extraoracional "pero", en la frase: ¡Pero fue tan dificil todas las cosas! En esta última, se registra que la entrevistada llega a una conclusión contraria a la esperada por la regla, pero que el antecedente no está en la oración local inmediata, sino en todo el segmento textual anterior, en el que María expone los recursos que posee para adaptarse a la nueva situación.

Pensamos, además, y a modo de hipótesis, que María intentaría prevenir una situación temida, que le generaría un dolor mayor, esto es, que alguno de sus hijos varones fuera machi.

Según la creencia mapuche, los machis hombres pueden recibir el don de parientes del sexo femenino o masculino. En el caso de la mujer, en cambio, reciben sus espíritus, para luego aceptar el don, de parientes por parte de la madre. En este caso, María no podría recibir el don, teniendo en cuenta aquello que la entrevistadora relata como uno de los momentos mas movilizantes durante la entrevista: "hubo momentos que su tono y expresión facial demostraba mucha pena, como cuando contó que no conoció a sus padres, en especial, su mamá”.

Entre los indicadores, inferimos que María insistiría para que su marido acepte el don, como modo de "responsabilizarse", cuestión que relata de modo imperativo, no solo por las posibles consecuencias que conllevaría no hacerlo (sobre la persona de éste último), sino también como la única forma, tal vez, de evitar aquello que su suegra, Garante Genérico (Anscombre, 1998 en Fernández, 2006), le habría contado. La suegra no quería que su hijo fuera

en la siguiente expresión: “yo misma le hacía la oración, le preparaba los remedios y ahí me despertaban [el espíritu] a las 5 de la mañana, “ique se levante su machi, que haga oración!”. 
machi, porque "sufren mucho". Además, parecería que a partir de ese momento en el nudo de la narración, María comienza a relatar las distintas experiencias en las que involucra a personajes por fuera del ámbito familiar para que "confirmen" el don. Necesidad que no parece haber sido imperante antes de ese suceso, ya que cuando escucha por parte de un familiar de su esposo (la prima) que existían antepasados machi en esa familia y esta mujer le dice explícitamente: "algún día el Manuel va a ser machi", María responde con un "modalizante hipotético": "quizás".

Igualmente, la entrevistada presuponía, desde antes, que la causa de los malestares de su esposo y sus enfermedades, se debían al "llamado" de ser machi. Al comentar su conversación con la prima de Manuel, utiliza una pregunta retórica: "porque a mi me dan muchos sueños y me pasan cosas, ¿porqué?", utilizando una afirmación en la que establece una conexión causal. Algo similar se registra en relación a la conversación con la suegra, cuando dice: "a mi suegra le conté, “'porqué Manuel se enferma tanto? y yo me he soñado que él anda en esto ${ }^{28}$, en una cosa verde lo andan trayendo".

Tengamos en cuenta que en la cultura mapuche la enfermedad es vivida, junto a otros signos, como manifestación de la vocación de ser machi, la cual se presentaría antes de su iniciación y puede repetirse para recordarles su llamado ${ }^{2930}$. A la enfermedad de su hijo, se agrega aquello que la suegra le habría dicho en aquella conversación: " a lo mejor usted conoció mi antepasado de machi, en una de esas puede ser machi Manuel o uno de sus hijos o hija”. Es decir que "el peso" (por sus propios dichos) que lleva María estaría asociado a las consecuencias que implica para una madre y para su hijo, que éste sea machi. Tal vez, en este

\footnotetext{
${ }^{28}$ Deíctico que implica proximidad al yo, instala un Narrador homo en focalización interna

${ }^{29}$ Bacigalupo, A (2001): "La Voz del Kultrun en la Modernidad: Tradición y Cambio en La Terapéutica de Siete Machi Mapuche". Santiago: Editorial Universidad Católica de Chile.

${ }^{30}$ María relata además, un acontecimiento que podría apoyar nuestra hipótesis: "Le costó aceptar (refiriéndose al esposo). Yo pienso que tomó la decisión porque no estaba muy bien en la casa, se enfermaba mi hijo, hay veces era como un hospital la casa y mi hijo mayor casi se me fue [baja el tono de voz]. Entonces ahi las machi me dijeron, "te están tomando los hijos, te están tomando las pruebas, ¿qué es lo que va a hacer?; si realmente cree, tiene que tomar el don".
} 
sentido, es que la entrevistada utiliza recursos discursivos que le permiten sostener sus argumentaciones, insistiendo para ello con la reconstrucción de cadenas causales.

\section{III. e) Contrato de comunicación y ejercicio de poder en la relación Er-Edo.}

Retomando el análisis de la entrevista, desde el aporte de la Etnografía del habla, podemos pensar que, si bien la entrevistadora supone un posible "acuerdo" ${ }^{31}$ con María, en la lógica de la vinculación narrador - narratorio, definiéndose para ello como una "representante de los pueblos originarios", la entrevistadora sostiene: "El hecho de ser representante de la cultura originaria, me permitiría entrar en la cultura mapuche, desde la mirada femenina del cuidado de la salud". Sugiriendo, que estarían dadas ciertas condiciones subjetivas para que se genere un "ambiente de confianza mutua". Esto, no parecería coincidir con la forma en que la entrevistada se erige en autoridad, ejerciendo un poder - saber, sobre todo lo que se refiere a las "creencias indígenas" (mapuche en este caso).

Apelando además a un "Garante Genérico", en las figuras de su suegra (recordemos la valoración positiva de la ancianidad en las culturas indígenas); y en las otras machis, que al incluirlas en el relato, lo hace utilizando un operador de formulación que transmite satisfactoriamente su intención comunicativa: "Después le pregunté a ella, (la machi) "¿bueno y qué va a pasar con él más adelante?"

María establece una distancia con el entrevistador utilizando como modalidad discursiva epistémica, el término "creo" para referirse a sus sueños: "yo tenía esa corazonada, porque yo

${ }^{31}$ En su trabajo, la entrevistadora comenta que su objetivo era acercarse al sector del centro de salud donde se trabaja con la utilización de la "medicina mapuche", siendo su intención, en un primer momento, entrevistar al machi que atiende en el lugar. Sin embargo, comenta: "En mis últimas visitas a ese lugar, tuve la oportunidad de compartir más con su esposa, quien alli es su ayudante y por primera vez me daba cuenta que su desconocido y silencioso rol era clave en la provisión de las condiciones necesarias para el ejercicio de las funciones del machi y la atención de los pacientes. Entonces, me propuse entrevistarla para conocer más sobre su papel y a la vez explorar su experiencia, como esposa de un machi. El hecho de ser representante de la cultura originaria, me permitiría entrar en la cultura mapuche, desde la mirada femenina del cuidado de la salud"' (Castellano Salas, 2007). 
antes tuve un sueño, yo creo mucho en mis sueños". La expresión "yo creo", parecería interpelar al otro (Er), quien se presenta como miembro de la cultura de la entrevistada, siendo sus creencias, de este modo, tal vez puestas en duda $^{32}$.

Esta distancia puede estar asociada con las instituciones que la entrevistadora representa: la medicina oficial y la educación, esta última por ser docente en la escuela de enfermería $^{33}$. Identificando a las instituciones como los receptores a quienes va auténticamente dirigido el mensaje. En forma implícita, la relación Edo - Er, respondería a una vinculación de tipo polémica: "el sujeto enunciador instaura mecanismos de dialogo polémico, con un discurso oficial, hegemónico, culturalmente valido a partir del cual se fundaría el hecho narrativo mismo" (Fernández, 2004).

Según Charaudeau (2006), el contrato de comunicación es lo que estructura una situación de intercambio verbal que cumple con las condiciones de realización de los actos de lenguaje que allí se producen, para que estos sean reconocidos como válidos, es decir que correspondan a una intencionalidad del sujeto comunicante y que puedan ser interpretados por el sujeto receptor-interpretante. Para Charaudeau (2006), el contrato es de lo que se habla antes de que cualquiera haya hablado, lo que es comprendido incluso antes de que se haya leído. Es decir que, el sistema de reconocimiento recíproco entre productor y receptor del acto de lenguaje que engendra el contrato, hace que el texto producido signifique, en primer lugar, por sus condiciones de comunicación.

En el género de la entrevista, el contrato de comunicación, implica una dimensión argumentativa, en el que la interacción Edo - Er (en nuestro caso), opera en dos sentidos: en el

\footnotetext{
${ }^{32}$ Por otro lado, la entrevistadora, con respecto a su experiencia durante esta entrevista, sostiene: "Me ha impactado mucho la simbología de los sueños, los que entregan mensajes que deben ser descifrados, comprendidos y acatados como guías o mandatos de vida. En este relato, su esposa tiene un sueño revelador del espiritu de machi”.

${ }^{33}$ En este sentido, la entrevista culmina con la siguiente afirmación: "Eso es lo que yo siempre pido a Ngünechen (deidad mapuche), que se recuperen las cosas antiguas, la cultura, como era antiguamente. Porque la gente ahora no conoce la parte espiritual, no se valora y yo pienso también que como ellos tienen educación [los jóvenes] entonces creen que ellos saben más que los que no tienen educación".
} 
de la coacción, a través de la necesidad de seguir ciertas reglas; y en el de la opción, en el planteo de estrategias. En este sentido, "el sujeto enunciador, para devenir tal, deberá "negociar" permanentemente sentidos con su enunciatario (en un sentido micro) y con el destinador justiciero (en un sentido macro) (Fernández, 2004)

\section{II.f) Elección de tiempos verbales: modo verbal fáctico.}

La utilización de un modo verbal fáctico, a través de la recurrencia del modo indicativo de los verbos en la entrevista, nos indicaría una necesidad en la entrevistada de demostrar los obstáculos que aún debe superar para acompañar y fortalecer el "Don" de la sanación en su marido, devenido machi: "Entonces, por eso el tomó la responsabilidad y todo este trabajo y el peso que llevo yo". Cuando María relata el momento en qué sus hijos le preguntaron porqué el padre "se había hecho machi", comenta: "para ayudar a la familia, para ayudar a la gente (1) y también si no es machi puede quedar en silla de ruedas (2), porque el daño es muy complicado, si tu no toma responsabilidad o no asume, te pasan cosas y te dan pruebas de arriba (3)". Estableciendo así las causas (1), consecuencias (2) y resultados (3). Al focalizar en las consecuencias, María asumiría la responsabilidad en su rol como "intermediadora" entre los espíritus y el machi, incitando por momentos al marido, y en relación tal vez a la hipótesis antes mencionada, para que asuma "responsablemente" su rol. En cuanto a este punto expresa: "en un momento me dijo (refiriéndose al marido) "no voy a atender más gente”. Yo le dije "ino, tu quisiste tomar el don, tenís que seguir adelante, no podís echarte pie atrás! ¿Qué van a decir los mismos pacientes que usted ha sanado?" [En un tono firme y cuestionador]. Para fortalecer su compromiso e involucrar a los hijos, utilizaría como recurso una voz autorizada en salud para validar lo que le dicen los espíritus en sueños: “(...) uno tiene que estar porque está trabajando en salud con los doctores. A mi hijo igual le digo, a mi hijo mayor sobre todo, tu tenís que meterte más, apoyar, ayudar, si hay evento tenis ${ }^{34}$ que ir".

El modo indicativo en los verbos en la entrevista, se distribuyen en dos series: una que implica la combinación del dominio de una aspectualidad, vinculada a un tipo de acción

\footnotetext{
${ }^{34}$ Apelando a una modalidad discursiva de tipo deóntica, en la que utiliza la expresión del deber a través de imperativos que se reiteran recurrentemente durante toda la entrevista.
} 
puntual, así por ejemplo, encontramos; "fue”, "conté”, "se enfermó", "llevé”, "tuve”. Y un aspecto verbal durativo, presente en las siguientes expresiones: "todavía", "sentía", "decía”, "trabajaba", "estaban", "dejábamos", etc. Cumpliendo con el principio de "canonicidad", que le permite otorgar sentido a los sucesos, ya que se integran en una unidad narrativa más compleja.

Las menciones sobre la suegra, la prima, las machis y el espiritista, entre otros, podrían haber sido incluidos como testigos, para crear un verosímil realista que se mezcla en un relato con características "fantásticas". En un principio de la entrevista, María menciona tácitamente que su marido fue "elegido" para ser machi y lo expresa en forma explícita, luego de que comienza a incorporar en su relato a estos "testigos". De esta manera, antes de incluir a la prima del esposo, insinúa, en términos de presentimientos, corazonadas y sueños, que las causas de los malestares de éste, se asociaban con la posibilidad de que sea Machi: "No decía él, pero yo tenía esa corazonada, porque yo antes tuve un sueño", utilizando el conector causal (porque) y el "pero", como conector de causalidad implícita en qué se llega a una conclusión contraria a la esperada por la regla. Así como elige un "Operador de Concreción", en la expresión: "Es como la virgen cuando la llevan (...), y el Conector Contraargumentativo fuerte "Pero", al darle sentido a los padecimientos de su marido, sin mencionar explícitamente las causas de los mismos, pero insinuándolas, concluyendo con un "por eso": "porqué no quieres comer, dime qué te pasa?" [Tono más firme, recalcando cada palabra]. Pero yo presentía que algo tenía él, por eso 35 le pasaban esas cosas", indicadores registrados en el principio del relato.

\section{Conclusiones:}

En el marco de la entrevista, como género discursivo dentro de un contrato de comunicación, analizamos cómo la interacción Edo - Er opera en dos sentidos: 1- en el de la coacción, a través de la necesidad de seguir ciertas reglas; y 2- en el de la opción, en el planteo de estrategias. Para ello, nos basamos en el contexto más amplio del contrato de comunicación, el cual define el acto de lenguaje como dependiente de un conjunto de condiciones de realización que determinan, en parte, tanto el proceso de producción como de interpretación. Para Charaudeau (2006), estas condiciones conforman un acuerdo de co-construcción de sentido

\footnotetext{
${ }^{35}$ Modalidad causal de conexión de hechos
} 
entre dos sujetos que requieren una competencia psico-socio-lingüística. Dicha competencia supone, por parte de los dos sujetos, un reconocimiento recíproco del saber que está en juego (el propósito), de la relación de poder que se instaura entre ellos (las identidades) y de los comportamientos posibles (las instrucciones de los roles discursivos), constituyéndose así, según Charaudeau (2006), en una noción constitutiva de la comunicación lingüística.

Al presuponer la Eda al otro como representante de un discurso antagonista instaura un discurso polémico con él. Elige, para ello, una singular ubicación en el tiempo y en el espacio. En su relato predomina un modo verbal fáctico (indicativo), junto al uso de conectores causales, para demostrar los obstáculos que aún debe superar con el objetivo de acompañar y fortalecer el "don" de la sanación en su marido, devenido machi. Registramos, además, la inclusión de testigos que la avalan y la construcción de la figura del héroe, con la cual (hipotetizamos) se identifica.

Por otro lado, en cuanto a las posibilidades de crear enfoques interculturales en salud, consideramos que en la construcción salud-enfermedad colabora también la comunidad, como dadora de sentidos y confirmadora de "identidad", poniéndose en juego diversas creencias culturales. Consideramos que una integración y/o articulación de la "medicina popular" y la "oficial" resulta indispensable. Para esto último, resulta necesaria la implementación de un trabajo en equipos interdisciplinarios que permitan la superación de las "barreras", todavía vigentes, entre ambas medicinas. Hacia tal objetivo, se podría capacitar a estos equipos en temas que hacen a la diversidad cultural en salud, sobre todo en zonas rurales, en donde esta integración es una urgencia a la cual se debería dar prioridad.

Un trabajo conjunto de concientización colaboraría para que los agentes de salud (médicos campesinos), que no estén trabajando en estos equipos, colaboren en la prevención de padecimientos mayores y/o la complicación de enfermedades, e incluso la muerte, de aquellos que depositan su confianza en su atención. Resulta fundamental la derivación -a tiempo- de los casos que revisten algún tipo de gravedad, en lo inmediato y en los demás plazos, a los centros de salud, mientras el proceso de integración cultural, en plena gestación, se siga consolidando.

\section{Bibliografía:}


BACIGALUPO, A (2001): "La Voz del Kultrun en la Modernidad: Tradición y Cambio en La Terapéutica de Siete Machi Mapuche”. Santiago: Editorial Universidad Católica de Chile. [ Links ]

BARALE, G Y FERNÁNDEZ, A (2009): "El rol de la medicina popular en el NOA" en Cuadernos de ética, estética, mito y religión 3. Reflexiones sobre cultura contemporánea. Tucumán-Argentina: Facultad de Filosofía y Letras-Universidad Nacional de Tucumán.

BLEGER, J (1064): “La entrevista psicológica: su empleo en el diagnóstico y la investigación". Universidad de Buenos Aires, Buenos Aires- Argentina.

CASTELLANO SALAS, Á. Guardiana del espíritu de un machi y sus sueños.Index Enferm [online]. 2007, vol.16, n.57 [citado 2013-03-07], pp. 65-69. Disponible en: $<$ http://scielo.isciii.es/scielo.php?script=sci_arttext\&pid=S113212962007000200014\&lng= es\&nrm=iso >. ISSN 1132-1296.

CHARAUDEAU (2004): “La problemática de los géneros. De la situación a la construcción textual” en Signos, Vol.37, № 56, Universidad de Valparaíso, Chile.

CHARAUDEAU (2006): "El contrato de comunicación en una perspectiva lingüística: Normas psicosociales y normas discursivas". Opcion [online]. 2006, vol.22, n.49 [citado 2014-04-30], pp. 38-54 . Disponible $<$ http://www.scielo.org.ve/scielo.php?script=sci_arttext\&pid=S101215872006000100004\&lng=es\&nrm=iso $>$. ISSN 1012-1587.

FERNÁNDEZ GÜIZZETTI, G (1983): "Entre el ámbito del significado y el mundo de los objetos: los referentes psicoculturales del signo lingüístico" en Suplemento Antropológico, Universidad Católica de Asunción del Paraguay.

FERNÁNDEZ, MR (1998): “Lenguaje, pensamiento i-rrealidad”, en Revista de la Escuela de Antropología $\mathrm{N}^{\mathrm{O}} 4$.

FERNÁNDEZ, MR (1999): "Discurso y ejercicio del poder: la entrevista" en Revista de Letras $\mathrm{N}^{\mathrm{o}} 8$, UNR, Rosario.

FERNÁNDEZ, MR (2004): "El relato autobiográfico y la construcción del yo" en Revista de la Escuela de Antropología No 7, Fac. de Humanidades y Artes, UNR.

FERNÁNDEZ, MR (2006): Hablar el mundo, Fundación de Patrimonio Histórico, versión en CD, Rosario. 
Papeles de Trabajo No 27 - Julio 2014 - ISSN 1852-4508

Centro de Estudios Interdisciplinarios en Etnolingüística y Antropología Socio-Cultural

FOUCAULT, M (1980): “Microfísica de poder”. Madrid: Editorial La Piqueta.

HERNÁNDEZ, FM (2012) “El discurso territorial”. Texto en preparación.

GRAMSCI, A (1978): “Antología”. Ediciones: Siglo XXI. Buenos Aires- Argentina.

LACAN, J. (1949) "El estadio del espejo como formador de la función del yo [je] tal como se nos revela en la experiencia psicoanalítica", en Escritos 1, Siglo XXI.

LACAN, J. (1961-62) Seminario IX: "La identificación”, Siglo XXI. 